\title{
Influence of Efficiency Factors of Gearing and Rope Drive in the Hoist Behaviour
}

\author{
Vöth Stefan ${ }^{1, *}$, Alexander Korotkov ${ }^{2}$ \\ ${ }^{1}$ Technichal University Georg Agricola, Bochum, Germany \\ ${ }^{2}$ State Technichal University Kuzbass, Kemerovo, Russia
}

\begin{abstract}
The braking effect of hoists is influenced by the efficiencies of the installed components. It is foreseeable that the occurring losses lead to greater decelerations than lossless consideration. This article considers the efficiency and its description. He goes from an easily comprehensible description for a simple mechanical system for the description of a hoist with its temporally and locally variable energy inputs and energy outputs. The article presents a general equation for the system acceleration of hoists. This general equation potentially takes into account three brakes: motor brake, service brake and safety brake and two efficiencies: Gearing efficiency and rope drive efficiency. Finally, the braking distances and the required braking torques for braking with the safety brake of the reference hoist are shown. The contents are inspired by the VDI Technical Committee 304 Cranes.
\end{abstract}

\section{Initial Situation}

A characteristic feature of mechanical drives is loss. It occurs in various forms, e.g. Friction forces between rigid bodies in bearings, shear forces in lubricants of gears or power losses due to stiffness of ropes in pulleys. Losses reduce the power delivered by the drive. As a result, the driven parts of the powertrain are driven by a power lower than the power originally supplied to the system. The loss can be described by the physics in detail or by the efficiency.

Mechanical performance is the product of static and kinematic variables. When the kinematic variables are coupled via fixed ratios, the loss manifests itself in a reduction in static magnitudes, e.g. the torques in rotation systems:

$$
\eta=\frac{P_{\text {input }}-P_{\text {loss }}}{P_{\text {input }}} \quad ; \quad \eta=\frac{M_{\text {input }}-M_{\text {loss }}}{M_{\text {input }}}
$$

For many systems with loss the situation is quite clear. They have only one position of energy supply to the system (engine) and only one position of energy extraction from the system (machine). The locations of the power supply and the energy extraction are located at one end of the drive train each. The power flow direction obviously shows in this case

\footnotetext{
*Corresponding author: stefan.voeth@thga.de
} 
from the engine to the machine. Equally clear are the amounts of energy at different locations of the powertrain, expressed in terms of efficiency.

For other systems, the situation is not that transparent. The number and positions of power input and output differ from the situation described or even change during operation. An example of this are hoists with their special operation:

- Change between lifting operation and lowering operation.

- Change of the load.

- Activation, deactivation and control of motors.

- Activation and deactivation of brakes.

- Steady operation or accelerated operation.

Due to this, the power flow direction is not that obvious at least in certain parts of the powertrain. This also applies subsequently to the relationships of the different amounts of energy expressed in terms of efficiency.

In the following, the system hoist is analysed to describe the relationships for energy losses in hoists. With low efficiency components involved, this is of interest in terms of the resulting brake dimensions and braking distances due to e.g. Emergency stop and off due to response of the hoisting limit switch.

\section{Approach}

To illustrate the approach, the following situation is considered: A system consists of two masses, which are connected by a rigid rod with the efficiency $\eta$. The one-degree-offreedom system can move horizontally and has the current speed $\mathrm{v}$.
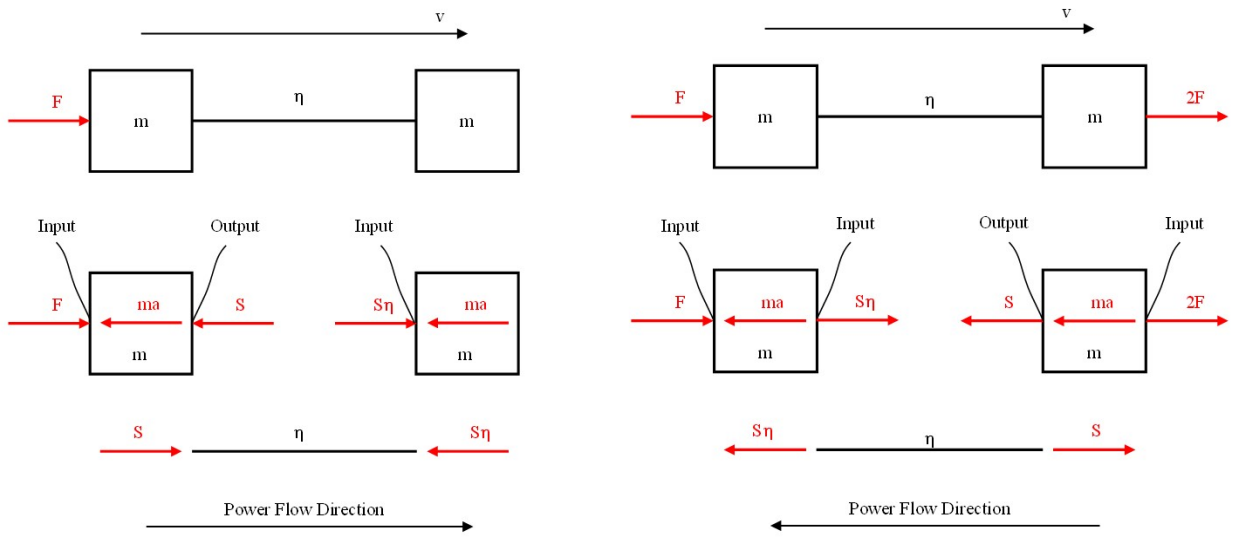

Fig. 1. Two mass model with loss, left case a), right case b).

In case a) a force $\mathrm{F}$ is exerted on the left mass. After cutting free the masses and the rod and determining all external and internal forces on the resulting three objects, it is obvious:

- There are losses, action force and reaction force on the rod are not the same size.

- Since the drive position is on the left, the power flow direction obviously points from left to right.

- A force vector of the force pairs between the system elements has the same direction as the speed vector. This indicates an energy input plane.

- A force vector of the force pairs between the system elements has opposite direction to the speed vector. This indicates an energy output plane.

- Within the system, the power flows from the energy output planes to the energy input planes.

- The rod is under pressure. 
The acceleration and the rod force take the following quantities:

$$
\dot{v}=\frac{\eta}{1+\eta} \frac{F}{m} \quad ; \quad S=\frac{1}{1+\eta} F
$$

In a system $\mathrm{b}$ ) in which the right-hand mass is driven by an additional force $2 \mathrm{~F}$, it can be seen that all these properties are generally still valid. Since the main drive position is now at the right mass, the direction of power flow obviously points from right to left. The rod is under tension. It is reasonable to assume that mechanical systems of more complex structure also behave according to these rules

The acceleration and the rod force take the following quantities:

$$
\dot{v}=\frac{1+2 \eta}{1+\eta} \frac{F}{m} \quad ; \quad S=\frac{1}{1+\eta} F
$$

\section{Rigid Body Model}

These findings are now applied to a hoist. For different operating conditions, the described analysis is performed. This results in particular in the vectors of the internal forces, of the object speeds and thus of the power flow direction.

The analyzes are carried out on the basis of a rigid body model for the hoist described in [1]. The model contains three discrete masses: Motor mass, rope drum mass and mass of the load attachmet device plus attached load. The kinematic relationships of the model are described by the gear ratio, the rope drive ratio and the rope drum radius. The speeds of all masses are positively defined in the hoisting direction. The model includes the following parameters. In addition to [1] efficiencies are introduced for the gearbox and the rope drive:

Table 1. System properties.

\begin{tabular}{|l|l|c|}
\hline Parameter & Quality & Quantity \\
\hline Motor mass & $\theta_{1}$ in $\mathrm{kgm}^{2}$ & 20 \\
\hline Rope drum mass & $\theta_{2}$ in $\mathrm{kgm}^{2}$ & 500 \\
\hline Gearing ratio & $\mathrm{i}_{\mathrm{G}}$ in 1 & 26.2 \\
\hline Rope drive ratio & $\mathrm{is}_{\mathrm{S}}$ in 1 & 4 \\
\hline Gearing efficiency & $\eta_{\mathrm{G}}$ in 1 & 0.96 \\
\hline Rope drive efficiency & $\eta_{\mathrm{S}}$ in 1 & 0.92 \\
\hline Rope drum radius & $\mathrm{r}$ in $\mathrm{m}$ & 0.5 \\
\hline Mass load attachment device & $\mathrm{m}_{\mathrm{LAM}}$ in $\mathrm{t}$ & 10 \\
\hline Rated capacity & $\mathrm{m}_{\mathrm{SWL}}$ in $\mathrm{t}$ & 52 \\
\hline Operating factor service brake & $\mathrm{BF}_{\mathrm{BB}}$ in 1 & 2.0 \\
\hline Operating factor safety brake & $\mathrm{BF}$ SB in 1 & 1.7 \\
\hline
\end{tabular}

Ignoring losses, the following equation describes the acceleration of the motor shaft for all operating conditions.

$$
\dot{\omega}_{1}=\frac{M_{M} \mp M_{H B} \mp \frac{M_{S B}}{i_{G}}-\frac{g r}{i_{G} i_{S}}\left(m_{\text {LAM }}+m_{\text {Last }}\right)}{\theta_{1}+\frac{\theta_{2}}{i_{G}{ }^{2}}+\frac{r^{2}}{i_{G}{ }^{2} i_{S}{ }^{2}}\left(m_{\text {LAM }}+m_{\text {Last }}\right)}
$$




\section{Internal Forces during Hoisting}

Taking into account losses, the required engine torque is greater than the static load torque. The losses must be additionally covered by the engine.

The deceleration for all braking operations out of lifting increases, taking into account losses. The losses "help" to accomplish the task.

During steady-state operation, the gearing input torque is higher than the static gearing input torque because of the losses that occur. When braking with the service brake, the gearing input shaft is relieved. During braking with the safety brake, the gearing input shaft is additionally loaded.

The highest gearing input torque occurs during braking of the rated capacity with the safety brake. The highest gearing input torque span occurs during the operating state change from the braking of the dead load with the service brake to the braking of the dead load with the service brake + safety brake.

\section{Internal forces during Lowering}

Taking into account losses, the engine torque is lower than the static load torque. The losses "help" to accomplish the task. The deceleration for all braking operations out of lowering increases, taking into account losses. The losses "help" to accomplish the task. In steadystate operation, the gearing input torque is lower than the static gearing input torque because of the losses occurring. When braking with the service brake, the gearing input shaft is slightly relieved or loaded. During braking operations with the safety brake, the gearing input shaft undergoes a change of direction of the gearing input torque. The highest gearing input torque occurs during braking of the dead load with the safety brake. The highest span of the gearing input torque occurs during the operating state change from steady state operation with dead load to the braking of the dead load with the safety brake.
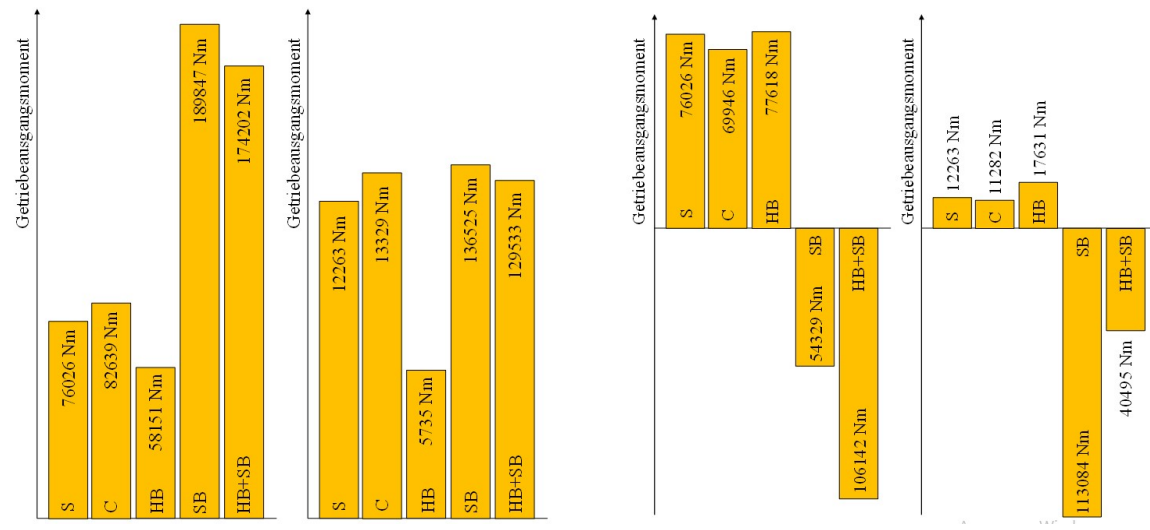

Fig. 2. Gearing input / output torque for lowering; S Statical condition, C Steady state, HB Deceleration with service brake, SB Deceleration with safety brake, HB+SB Deceleration with service brake and safety brake.

\section{Loading Events}

The largest loads of the gearing input shaft are connected with lifting operations. The largest gearing input torque occurs during the braking of the rated capacity with the safety brake. The largest gearing input torque range occurs during the operating state change from 
the braking of the dead load with the service brake to the braking of the dead load with the service brake and the safety brake.

The largest gearing output torque occurs when braking the rated capacity from the lifting operation with the safety brake. The largest gearing output torque span occurs during the operating state change from the steady state operation of the dead load to the braking of the dead load with the safety brake.

The largest rope force occurs during the steady lift operation of the rated capacity. The largest rope force span occurs during the operating state change from the steady-state lifting operation of the rated capacity to the braking of the rated capacity with the service brake.

\section{System Accelerations}

Taking losses into account, the system accelerations for the various operating states are determined as follows:

Table 2. Amount of system acceleration dependent on mode of operation.

\begin{tabular}{|l|l|c|c|c|}
\hline \multicolumn{2}{|l|}{$\begin{array}{l}\text { Amount of system } \\
\text { acceleration in s }\end{array}$} & $\begin{array}{c}\text { Service } \\
\text { brake }\end{array}$ & $\begin{array}{c}\text { Safety } \\
\text { brake }\end{array}$ & $\begin{array}{c}\text { Service brake } \\
+ \\
\text { Safety brake }\end{array}$ \\
\hline \multirow{2}{*}{ Hoisting } & Rated Capacity & 301,4 & 271,4 & 547,5 \\
\cline { 2 - 5 } & Dead load & 405,6 & 377,1 & 636,3 \\
\hline \multirow{2}{*}{ Lowering } & Rated Capacity & 257,7 & 224,8 & 501,0 \\
\cline { 2 - 5 } & Dead load & 147,8 & 108,0 & 370,5 \\
\hline
\end{tabular}

General description of accelerations

For braking procedures using the service brake and / or the safety brake, a general equation for the system acceleration taking into account the efficiencies of the gearing and the rope drive can be given:

$$
\dot{\omega}_{1}=\frac{\mp M_{B B} \mp \frac{1}{\eta_{G}{ }^{*}} \frac{M_{S B}}{i_{G}}-\frac{1}{\eta_{G}{ }^{*} \eta_{S}{ }^{* *}} \frac{m g r}{i_{G} i_{S}}}{\theta_{1}+\frac{1}{\eta_{G}{ }^{*}} \frac{\theta_{2}}{i_{G}{ }^{2}}+\frac{1}{\eta_{G}{ }^{*} \eta_{S}{ }^{* *}} \frac{m r^{2}}{i_{G}{ }^{2} i_{S}{ }^{2}}}
$$

Hoisting:

Lowering:

Lowering, safety brake active:

Others:

$$
\begin{aligned}
& \mp=-, \eta G^{*}=\eta G \\
& \bar{\mp}=+, \eta G^{*}=\eta G^{-1} \\
& \eta S^{* *}=\eta S^{-1} \\
& \eta S^{* *}=\eta S
\end{aligned}
$$

\section{Braking Paths and Braking Torques}

The accelerations dependent on the efficiencies result in changes in the braking distance. The losses described by the efficiencies inhibit the movement and thus lead to shorter braking distances. Of particular interest is certainly the braking distance for emergency stop out of lowering of the rated capacity. The evaluation results for a spectrum of the gearing

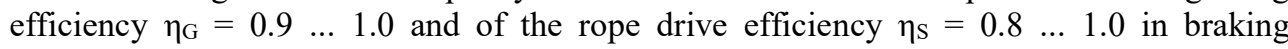
distances in the range of $\mathrm{s}_{\mathrm{Brems}}=440 \mathrm{~mm} \ldots 640 \mathrm{~mm}$.

If a certain braking distance is to be achieved, in turn the necessary braking torque depends on the efficiencies. For a spectrum of the gearing efficiency $\eta_{\mathrm{G}}=0.9 \ldots 1.0$ and of the rope drive efficiency $\eta_{\mathrm{S}}=0.8 \ldots 1.0$ the evaluation results in operating factors of the safety brake $[1]$ of $\mathrm{BF}_{\mathrm{SB}}=1.8 \ldots 2.2$. 


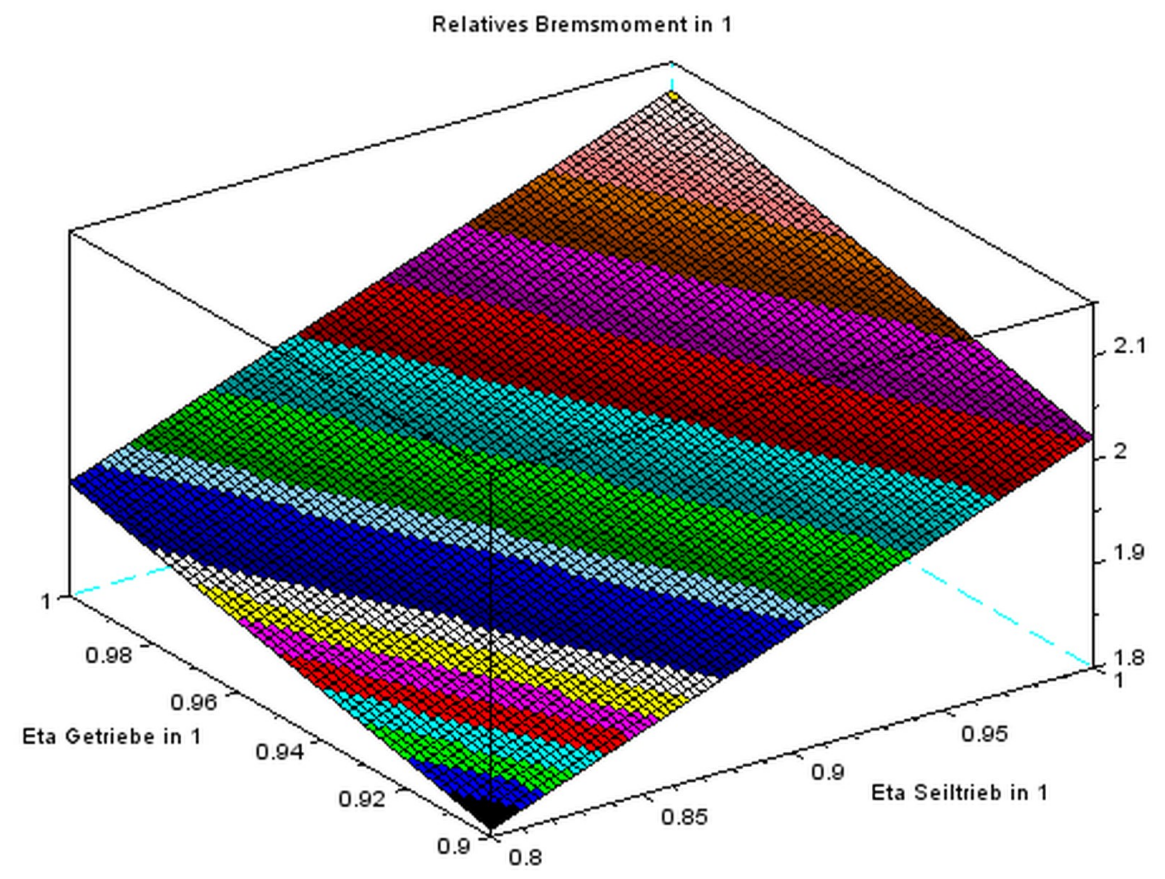

Fig. 3. Relative braking torque BFSB dependent on the efficiencies of gearing and rope drive.

\section{References}

1. S. Vöth, Hebezeuge und Fördermittel, 3 (2015)

2. A. Rücker, J. Fottner, Kranfachtagung, 3 (2018)

3. K.A. Goncharov, I.A. Denisov, Research Journal of State Technical University Briansk, 4 (2005)

1. D. Wehner, Kran \& Bühne, 2:3, (2017)

2. G. Steinbach, M. Anders, D. Ryk, Drahtseile in Seiltrieben nach DIN EN 1, 23 (2016)

3. D. Wehner, Bauportal, 5, 66 (2015)

4. D. Wehner, $\mathrm{f}+\mathrm{h}, \mathbf{1}(\mathbf{2}), 70(2015)$

5. B. Samec, T. Lerher, I. Potrc, Material handling, Construction and Logistics (AVBN, Vienna, 2015)

6. K. Jarmai, J. Farkas, Int. Conf. on Eng. Sc., 5, 45 (2015)

7. M. Kleeberger, S. Schneidler, W.A. Günthner, Untersuchung der dynamischen beanspruchungen bei Gittermast-Fahrzeugkranen und Vergleich mit der quasistatischen Auslegung nach Norm, (Kranfachtagung, Magdeburg, 2014)

8. D. Wehner, Neue Europanorm für Krane, Bauportal, 3, 44 (2013)

9. S. Schneidler, M. Kleeberger, Kranfachtagung, 3, 24 (2012)

10. D. Wehner, Bauportal, 2, 31 (2011)

11. W. Warkenthin, DIN EN 13001-2, 47, 10 (2007) 
12. D. Wehner, Berechnungsnorm für Krane, 3, 124 (2007)

13. S. Markusik, Transport Problems, 2, 1 (2007)

14. J. Gentzsch, Kranfachtagung, 3, 26 (2006)

15. G. Sedlaczek, Ch. Müller, S. Hoehler, D. Schäfer, Stahlbau, 75:11, 939 (2006)

16. O. Kempkes, J. Scholten, G. Wagner, Wege zur Konstruktion sicherer und wirtschaftlicher Krane, 7:8, 356 (2005)

17. M. Golder,: Kranfachtagung, 5, 3 (2004)

18. G. Wagner, J. Scholten, H. Haensel, Kranfachtagung, 5, 22 (2003)

19. R. Obretinow, G. Wagner, DIN 15018, Stahlbau, 4, 218 (2000)

20. S. Vöth, f+h, 1:2, 65 (1996)

21. R. Obretinow, HF, 10, 431 (1996)

22. R. Obretinow, HF, 11, 530 (1996)

23. W. Warkenthin, Klassifizierung eines Krans nach Betriebsbedingungen zu den Beanspruchungsgruppen des Tragwerkes (Fachtagung Fördertechnik, Dresden, 1995) 